\title{
ENFERMAGEM PEDIÁTRICA E O RELACIONAMENTO COM FAMILIARES
}

Mariana de Ávila Pereira Teixeira

Acadêmica de Enfermagem do Centro Universitário de Volta Redonda (UniFOA), Volta Redonda (RJ), Brasil.

Milena Carine Coutinho

Acadêmica de Enfermagem do Centro Universitário de Volta Redonda (UniFOA), Volta Redonda (RJ), Brasil.

\section{Ana Lucia Torres Devezas Souza}

Mestre em Ensino de Ciências da Saúde e Meio Ambiente; Docente no Curso de Enfermagem do Centro Universitário de Volta Redonda (UniFOA), Volta Redonda (RJ), Brasil.

\section{Renata Martins da Silva}

Doutoranda no Programa de Pós-Graduação em Enfermagem e Biociências (PPGENFBIO) pela Universidade Federal do Estado do Rio de Janeiro (UNIRIO); Docente no Curso de Enfermagem do Centro Universitário de Volta Redonda (UniFOA), Volta Redonda (RJ), Brasil.

E-mail: renataenfprofessora@gmail.com
RESUMO: Objetivos: descrever a opinião da equipe de enfermagem sobre a participação de mães/familiares na assistência à criança internada; apontar as principais dificuldades referidas pela equipe durante a assistência à criança internada na presença dos responsáveis e analisar a influência do responsável da criança na qualidade da assistência prestada por essa equipe. Método: a coleta de dados foi realizada em dois hospitais, no município de Volta Redonda (RJ). Os sujeitos do estudo foram 36 profissionais da equipe de enfermagem que responderam a um questionário elaborado pelos próprios autores com questões abertas e fechadas. Estudo descritivo com abordagem qualitativa. Resultados: para maioria (81\%) dos profissionais a presença dos pais é fundamental, porém podem existir dificuldades quando há intervenção dos pais durante os procedimentos invasivos. Conclusão: demonstra-se assim a importância da relação entre equipe e familiar para o desenvolvimento de uma assistência de qualidade à criança.

PALAVRAS-CHAVE: Enfermagem pediátrica; Criança hospitalizada; Pais.

\section{PEDIATRIC NURSING AND RELATIONSHIP WITH FAMILY MEMBERS}

ABSTRACT: Aims: current assay describes the opinion of the Nursing Team on the participation of mother/family members caring for the hospitalized child; pinpoints the main difficulties during assistance to the child in the presence of family members and analyzes the influence of parents on quality assistance given by the team. Data collected occurred in two hospitals in Volta Redonda RJ Brazil. Subjects were 36 health professionals from the Nursing Team who answered an open and close-question questionnaire prepared by the authors. In the case of $81 \%$ of professionals, the presence of family members is basic even though difficulties may arise when parents interfere during invasive procedures. Relationship between team and family members is highly important for the development of quality assistance to children.

KEY WORDS: Pediatric nursing; Hospitalized children; Parents.

\section{INTRODUÇÃO}

Este artigo aborda o discurso da equipe de enfermagem sobre a participação de familiares na assistência à criança internada em unidades pediátricas e pronto socorro pediátrico. A mãe e/ou familiar devem ser reconhecidos pela equipe de enfermagem como 
parceiros no cuidado e na recuperação da criança, pois a mãe é seu elo com o ambiente externo e quem identifica no ambiente hospitalar as necessidades desta criança (HOCKENBERRY et al, 2014).

Não cabe ao responsável pela criança fazer as tarefas da enfermagem, mas o enfermeiro busca uma relação de cuidado compartilhado, reconhecendo o papel natural de cuidador que o responsável exerce. Seu acompanhante poderá tomar decisões sobre o cuidado com a criança, interferindo ou não na assistência quando entender necessário. (COLLET; ROCHA, 2004).

A família da criança deve ser inserida no contexto da sua internação, levando-se em conta todos seus direitos e deveres no âmbito hospitalar e na função de acompanhante, e deve servir de elo entre a equipe de enfermagem e a criança hospitalizada. Essa questão tem demandado novas formas de organização na dinâmica do cuidado de enfermagem. No caso da internação pediátrica, para se prestar um cuidado integral à criança, torna-se imprescindível voltar à atenção para as necessidades da família, desenvolvendo, assim, uma proposta de cuidado centrado na díade criança-família [...] (XAVIER et al., 2014).

O modo de enfrentar a hospitalização do filho é singular para cada família, a realidade hospitalar é dolorosa e difícil e as reações dos responsáveis neste ambiente são singulares, afinal ocorre uma quebra nas rotinas dessa família. Sendo assim o enfermeiro deve respeitar, apoiar, encorajar e enfatizar competências e potencialidades do familiar na vida dessa criança e o cuidado deve ser sistematizado e holístico, a fim de promover assistência de qualidade e também o cuidado emocional (HOCKENBERRY et al., 2014).

O enfermeiro deve dar ênfase ao bem-estar da criança estabelecendo uma relação de confiança, pois assim ajudará na aproximação da equipe para realizar os devidos cuidados com consentimento dos familiares. Esta aproximação deve ser de forma mais amena, para suavizar a hostilidade do ambiente hospitalar, pois os profissionais acreditam que a criança sinta-se mais confiante e esclarecida a respeito dos procedimentos, não demonstrando medo na presença da mãe (ROSSI; RODRIGUES, 2010).

A mãe e a criança possuem uma relação de afeto, portanto quando é oferecida a oportunidade da participação dela no cuidado, haverá possibilidade de maior aceitação de ambas, quanto aos procedimentos que serão realizados. A equipe de enfermagem que reconhece esta participação no cuidado poderá ter boa aliada para a realização das atividades diárias e a mãe poderá desenvolver o sentimento de confiança. Porém quando é violada sua autonomia, a mãe/familiar fica submetida às condições da instituição e dos profissionais de saúde e às vezes não questionam por não saberem a quem recorrer (COLLET; ROCHA, 2003).

Deve-se então transformar a presença do familiar/ responsável em uma permanência agradável, além de preparar a equipe perante a família para uma melhor flexibilidade e organização dos cuidados, trazendo de volta a autonomia pelo acolhimento e diálogo aberto entre ambos a fim de minimizar dificuldades e favorecer a recuperação da criança (MINISTÉRIO DA SAÚDE, 2010).

Albuquerque et al. (2013) salientam que dentre as principais dificuldades identificadas na interação entre a família e a equipe de enfermagem pediátrica estão a falta de comunicação e de informação sobre o tratamento, além de tratamento desigual entre as crianças. Quanto às facilidades mais citadas nesta interação estão o fato de o profissional ser bom tecnicamente, orientar sobre o tratamento, ter bom relacionamento e manter o diálogo e apoio à família.

Os objetivos da pesquisa foram descrever a opinião da equipe de enfermagem sobre a participação de mães/familiares na assistência à criança internada; apontar as principais dificuldades referidas pela equipe durante a assistência à criança internada na presença dos responsáveis e analisar a influência do responsável da criança na qualidade da assistência prestada por essa equipe.

\section{METODOLOGIA}

Trata-se de um estudo descritivo e com abordagem qualitativa em que se buscou discutir o relacionamento entre a equipe de enfermagem e responsáveis pela criança internada em unidades pediátricas e prontos socorros pediátricos.

O cenário contou com dois hospitais sendo um privado de médio porte e outro público de grande porte, 
do município de Volta Redonda, interior do Estado do Rio de Janeiro (RJ). Ambos com atendimento de Urgência e internação pediátricas e que contam com equipe completa de enfermagem 24 horas.

Os sujeitos de estudo foram enfermeiros e técnicos de enfermagem atuantes nessas unidades. Os critérios de exclusão foram os enfermeiros e técnicos de enfermagem que atuam nos setores de classificação de risco da unidade de urgência e emergência, clínica médica, clínica cirúrgica, unidade coronariana e unidade de tratamento intensivo e todos os profissionais que estavam em período de férias e dispensa médica durante o período de coleta de dados.

O universo dos sujeitos de estudo foi de 36 integrantes da equipe de enfermagem atuantes em ambos os hospitais e que aceitaram responder ao questionário elaborado pelos autores com perguntas abertas e fechadas após receberem previamente um Termo de Consentimento Livre e Esclarecido (TCLE) nos meses de setembro e outubro de 2016.

A análise de dados foi por similaridade de respostas e permitiu formar as seguintes categorias: procedimentos invasivos na criança; expressões sentimentais dos pais e cooperação dos pais e o reflexo na qualidade da assistência.

Houve aprovação da pesquisa pelo Comitê de Ética em Pesquisa com Seres Humanos do UniFOA, sob o parecer consubstanciado $\mathrm{n}^{\mathrm{0}} 1.666 .780$.

\section{RESULTADOS}

Evidenciou-se que 34 profissionais, do total de 36 , eram do sexo feminino e dois eram do sexo masculino, o que representa um percentual de $94 \%$ feminino e $6 \%$ masculino. A idade variou entre 20 e 69 anos, uma média de 12 anos de trabalho em setores de pediatria.

Mediante o questionamento sobre como a equipe de enfermagem identifica a intervenção/ participação no cuidado/ assistência com a criança internada, obteve-se o percentual de $81 \%$ dos participantes da pesquisa dizendo que a participação dos responsáveis ajuda durante a internação, porque a presença dos pais dá segurança à criança. Enquanto que 11\% ressaltam que essa participação atrapalha, pois acreditam que os pais com o seu nervosismo e ansiedade deixam as crianças mais agitadas e menos colaborativas. E, ainda, $8 \%$ disseram que depende do responsável que está com a criança.

\section{DISCUSSÃO}

\subsection{PROCEDIMENTOS INVASIVOS NA CRIANÇA}

Toda mãe e/ou responsável tem satisfação de poder cuidar bem de seu filho, de modo que nada atrapalhe a saúde e a qualidade de vida da criança. No momento de internação o acompanhante pode sentir responsabilizado ou ter seu senso de proteção atingido pela necessidade do desenvolvimento de procedimentos realizados pela equipe de enfermagem, desta forma o mesmo deve ser encorajado a participar, estar perto, apoiar a criança e acolhê-la da melhor forma para trazer tranquilidade para ambos.

$\mathrm{O}$ apoio emocional oferecido à criança hospitalizada pelo acompanhante constitui-se em ferramenta facilitadora da recuperação que, se não bem trabalhada, poderá implicar na criação de uma barreira entre a enfermagem e a criança. Por isso "é de grande importância o estabelecimento de vínculos entre a família e a equipe de enfermagem, desde o início da internação, com a finalidade de atenuar o estresse provocado pela hospitalização" (MARQUES, 2014).

Dentre os procedimentos mais difíceis de serem realizados, destacaram-se: punções venosas, cateterismo vesical e administração de medicações. Tais procedimentos na visão da equipe de enfermagem permitem que os responsáveis e as crianças apresentem maior ansiedade e angústia, podendo dificultar a assistência.

Sendo assim torna-se necessário levar em consideração as expressões verbais e não verbais que conotam medo e angústia do familiar/responsável durante a realização de procedimentos invasivos e que causam dor na criança. $\mathrm{O}$ trabalho em equipe e a comunicação são primordiais no processo do cuidar dos pacientes internados na unidade pediátrica (PONTES et al., 2014).

Estudos mostram que a presença do familiar/ responsável durante a realização desses procedimentos 
invasivos vem se tornando mais comum com o passar dos anos, mas ainda não existem protocolos que norteiam essa conduta (REIS, 2015). Já a equipe de enfermagem apresenta opiniões distintas frente a presença dos pais durante procedimentos que causam dor na criança. Referem a falta de controle emocional apresentado pelos pais, prejuízo na execução dos procedimentos, limitação no ensino de profissionais em treinamento e o aumento do risco de processo legal como motivos de resistências quanto à presença dos pais. Entretanto, outros acreditam que com a participação da família, a criança apresenta maior controle da dor e redução do sofrimento, além ser oportuna a educação das famílias a respeito das condições do paciente.

O conhecimento por parte do familiar/ responsável da criança das necessidades de tratamento e os procedimentos que serão necessários pode trazer mais segurança e minimizar angústias durante os procedimentos invasivos. Esse vínculo só é possível frente a escuta aberta e sincera que reflita a autêntica preocupação com o bem-estar da criança por parte da equipe.

O déficit de conhecimento faz com que o familiar não reconheça as necessidades de tratamento da criança dificultando o trabalho da equipe de enfermagem que pode com seu conhecimento contribuir para aproximar a família e tornar a experiência menos traumática, mantendo a qualidade do cuidado. (SOUSA; GOMES; SANTOS, 2009).

Desta forma, o diálogo e atenção, as fragilidades apresentadas pelos familiares/responsáveis da criança, quando da realização de procedimentos invasivos pode proporcionar um ambiente mais acolhedor e que facilite a convivência e os momentos de trocas de experiências entre aqueles que conhecem bem a criança e aqueles que têm a responsabilidade profissional em prestar o cuidado mais adequado possível à criança que adoece.

\subsection{EXPRESSÕES SENTIMENTAIS DOS PAIS}

Segundo Schneider e Medeiros (2011), a hospitalização de uma criança muitas vezes desestrutura e faz com que pais ou responsáveis necessitem passar por modificações nas suas rotinas por um tempo, precisando se adaptar a esta nova situação, sendo esta estressora e criada de forma involuntária. E conforme Brassolatti e Veríssimo (2013), o cuidado prestado à criança deve ser intermediado pelos pais/responsáveis e o cuidador deve pautar esse cuidado sobre a família, a fim de se envolver na assistência.

Lopes (2012) salienta que durante a hospitalização a criança necessita de receber cuidados consistentes e que os pais continuem a exercer o seu papel parental, inspirando-lhes bem-estar, confiança e autoestima. Os enfermeiros, sendo os membros da equipe multiprofissional que mais tempo passam com a criança e sua família, têm maior proximidade e interação com ambos, desempenha papel fundamental na vivência desta situação de adoecimento. Sendo possível proporcionar aos pais a segurança necessária para desenvolverem uma visão positiva do processo de cuidado, minimizando a ansiedade vivenciada por muitos.

As equipes de enfermagem pesquisadas apontaram sentimentos como ansiedade, nervosismo e insegurança como os principais sentimentos vivenciados pelos pais de crianças internadas, fato que provavelmente deve-se à instabilidade sentimental ao ver sua criança internada e indefesa.

Os pais apresentam ansiedade e nervosismo diante dos procedimentos a serem realizados por estarem em um mundo desconhecido para eles e ainda por vivenciar a dor e desconforto da criança, típicos da internação, mas que nos pais causa sensação de impotência, fazendo que desperte a noção destes como sujeitos do cuidado e como um ser de direitos. Desta forma manifestam seus pensamentos e, é por estas manifestações que a equipe de saúde pode avaliar seu prestígio e imagem, frente a elas, e ainda ajudar no enfrentamento das questões visto que não é possível mudar o quadro que a criança apresenta, na maioria dos casos, no momento da assistência de enfermagem (XAVIER, 2013).

É necessário repensar as práticas do cuidado à criança hospitalizada, construindo uma relação dialógica como primeiro passo para a construção do vínculo entre profissionais de saúde e família. Para garantir o cuidar integral, deve-se considerar a necessidade de estabelecer vínculos, confiança e responsabilização entre família e profissionais da equipe (XAVIER, 2013). 
Em estudo realizado em Portugal, por Melo et al. (2014), foi discutida a participação efetiva dos pais e importância da interação com a equipe como a oportunidade de os pais de fazerem parte dos cuidados de forma ativa e esclarecida e como parceria, desta forma podendo lidar com seus sentimentos de forma esclarecida e menos traumática para todos os envolvidos.

O enfermeiro e sua equipe deverão, portanto, criar estratégias para que a família tenha segurança na assistência prestada, transformando seus sentimentos negativos em esperança na recuperação para que então possam transmitir conforto e estabilidade à criança, tornando-a mais colaborativa e facilitando assim o trabalho da equipe.

\subsection{COOPERAÇÃO DOS PAIS E O REFLEXO NA QUALI- DADE DA ASSISTÊNCIA}

A segurança e o nervosismo que os pais podem transmitir para as crianças surgem a partir do conhecimento que cada um possui sobre determinado procedimento a ser realizado. Observa-se que 39\% dos participantes responderam que a cooperação dos pais interfere na qualidade da assistência prestada. Outro fator mencionado é a falta de informação/ conhecimento prévio do responsável como sendo uma das principais dificuldades enfrentadas pela equipe de enfermagem, durante o cuidado e foi então apontada como um reflexo na qualidade dessa assistência.

\footnotetext{
Quando os pais são cooperativos, à assistência é melhor. (Profissional $\left.\mathrm{n}^{\mathrm{o}} 08\right)$;

Em determinados momentos atrapalham, por serem leigos em relação aos procedimentos. (Profissional $\mathrm{n}^{\circ}$ $09)$.

Por um lado o familiar acalma e acolhe a criança o que melhora a interação com os funcionários. Por outro lado a falta de entendimento da família atrapalha, pois não entende que a equipe está fazendo o serviço para melhor acolher o cliente. (Profissional $\left.\mathrm{n}^{\mathrm{O}} 14\right)$.
}

No cotidiano da equipe, o respeito pelo saber da clientela é essencial, pois a família pode não estar acostumada com as rotinas e padronizações do ambiente hospitalar, sendo assim o enfermeiro deve enfatizar frente a equipe a reflexão sobre o papel importante do familiar como elo com a criança hospitalizada, pois uma atitude que despreze o papel da família estará influenciando diretamente na essência do cuidado de enfermagem.

Cuidado este que reflete o compromisso da equipe de enfermagem frente às práticas de saúde voltadas para o cuidado integral e de qualidade. Sendo necessário o aprimoramento da equipe constantemente por meio de educação permanente oferecida pelas instituíçoes de saúde e discussão em instâncias colegiadas que visem atender às demandas dos pais e crianças internadas.

Torna-se assim fundamental que os profissionais da equipe de saúde, atuantes em unidades de pediatria criem e aprimorem o cuidado às crianças e aos seus familiares cuidadores, pelo planejamento dos cuidados oferecidos, discussões em reuniões de equipe e treinamentos, levando em conta o contexto social no qual estão inseridos e suas demandas específicas (XAVIER, 2013).

Os responsáveis pelas crianças hospitalizadas tornam-se fundamentais para transmitir segurança ao menor como pode ser observado nas falas abaixo:

$$
\begin{aligned}
& \text { O responsável por vezes servem de } \\
& \text { grande ajuda para a equipe de enfer- } \\
& \text { magem; influenciando positivamen- } \\
& \text { te na qualidade de atendimento. } \\
& \text { (Profissional n }{ }^{\circ} 22 \text { ). } \\
& \text { O responsável é de extrema impor- } \\
& \text { tância para acalmar a criança quan- } \\
& \text { do não permite que sua ansiedade } \\
& \text { transpareça. (Profissional no } 01 \text { ). } \\
& \text { O responsável é indispensável, po- } \\
& \text { rém em determinados casos, deixam } \\
& \text { as crianças mais agitadas, pois mos- } \\
& \text { tram seu nervosismo. (Profissional } \\
& n^{\circ} 06 \text { ) }
\end{aligned}
$$

Para que a equipe de enfermagem alcance o objetivo de ser efetiva e eficaz em cada procedimento, e que torne a presença dos familiares indispensável, é preciso reflexão coletiva por parte da equipe para assim estabelecer um diálogo aberto com os familiares a fim de satisfazer as necessidades emocionais dos pais e da criança. O profissional que transmite sentimentos para 0 familiar, que mostra boa vontade em mantê-lo informado e que explica cada procedimento ao acompanhante e a criança, de forma que ambos entendam e tenham 
liberdade de perguntar e esclarecer dúvidas tem a tendência de criar maior vínculo com o paciente.

Ao analisar as respostas percebeu-se que $81 \%$ dos participantes relataram que os pais auxiliam na qualidade da assistência de forma positiva, que transmitem segurança às crianças, tornando-as mais receptivas à equipe, para facilitar a realização da assistência, de modo a garantir melhor qualidade na prestação de serviços. Estudo realizado por Anjos (2015), quando trata de relatos de pais e equipe de enfermagem, reforça a participação dos pais como presença positiva e que corrobora para o cuidado prestado, pois percebe-se que ambos possuem o mesmo objetivo que é restabelecer a saúde da criança e que a presença do familiar acompanhante beneficia $o$ cuidado à criança.

É importante fornecer informações mais detalhadas perante o tratamento e o quadro clínico do paciente para esse familiar e confirmar que a equipe está buscando o melhor cuidado para essa criança. No seio familiar, esta se sente segura e protegida à medida que os laços afetivos vão se tornando cada vez mais fortes. Ao deparar-se com outro ambiente, portanto, é natural que a criança experimente sentimentos de medo e ameaça a esta condição de segurança (MARQUES, 2014).

Quando o familiar coopera e confia na equipe passa, como reflexo, esse sentimento para a criança, então se esta questão for ignorada consequentemente trará conflitos entre criança-enfermagem-acompanhante e assim afeta negativamente a qualidade da assistência e interfere no direito do paciente ao melhor cuidado possível.

Como limitação do estudo salienta-se a pesquisa ter sido realizada em dois hospitais de uma cidade do interior do Estado do Rio de Janeiro, retratando a realidade apenas desta região, embora pela revisão de literatura fosse possível observar que estudos realizados em outras regiões reforçam os achados desta pesquisa.

\section{CONCLUSÃO}

Conclui-se que para a maioria dos profissionais, a presença dos pais ajuda durante a assistência, pois estes promovem a tranquilidade das crianças pela segurança adquirida quando da presença do responsável. Outros relataram também que a presença dos pais depende das circunstâncias, do tipo de cuidado, do grau de entendimento dos pais dentre outros motivos. Constatouse, portanto, que a relação entre acompanhante e a equipe influenciam na recuperação, na cooperação e na compreensão do cuidado a ser prestado.

A maioria dos profissionais confirmou que possuem inúmeras dificuldades quando existe a intervenção dos pais durante o atendimento às crianças hospitalizadas. Fatores sentimentais dos pais podem provocar agitação das crianças e dificultar o acesso dos profissionais para desempenharem seu papel de cuidador. Palpites e pré-julgamentos durante as realizações de procedimentos invasivos, como punção venosa, cateterismo vesical, administração de medicações, entre outros fatores também foram citados como dificultadores quando na presença dos pais.

E por fim quanto à influência do responsável da criança na qualidade da assistência prestada pela equipe, conclui-se que esta pode influenciar positivamente no desenvolvimento das atividades. Ressalta-se ainda que uma escuta ativa voltada para a criança e seu acompanhante, acolhendo e ouvindo a ambos pode favorecer o elo entre os profissionais e o menor, devido ao familiar conhecer todas as limitações da criança podendo favorecer a assistência prestada.

\section{REFERÊNCIAS}

ALBUQUERQUE, D. B. et al. A família no cenário hospitalar pediátrico a partir da década de 1990: uma revisão integrativa. Cogitare Enferm., v.18, n.4, p. 78995, 2013.

ANJOS, C. O familiar acompanhante da criança e a equipe de enfermagem no centro de terapia intensivo pediátrico oncológico. 2015. 129f. Dissertação (Mestrado Acadêmico em Ciências do Cuidado em Saúde) - Universidade Federal Fluminense, Niterói, 2015.

BRASIL. Ministério da Saúde. Acolhimento nas práticas de produção de saúde. Secretaria de Atenção à Saúde, Núcleo Técnico da Política Nacional de Humanização. 2. 
ed. Brasília: Ministério da Saúde, 2010. 44p.

BRASSOLATTI, M. M.; VERÍSSIMO, RAMALLO, M. A presença dos pais e a promoção do desenvolvimento da criança hospitalizada: análise da literatura. Rev Soc Bras Enferm Pediatr., v.13, n. 1, p 37-45, 2013.

COLLET, N.; ROCHA, S. M. M. Criança Hospitalizada: Mãe E Enfermagem Compartilhando O Cuidado. Rev Latinoam Enfermagem., v.12, n.2, p. 191-7, 2004.

COLLET, N.; ROCHA, S. M. M. Participação E Autonomia Da Mãe No Cuidado Ao Filho Hospitalizado.Rev Bras Enferm, v.56, n.5, p. 260-264, 2003.

HOCKENBERRY, M. J.; WILSON, D. W. Fundamentos de enfermagem pediátrica. 9. ed. Rio de Janeiro: Elsevier, 2014

LOPES, N. M. Q. Parceria nos cuidados à criança nos serviços de pediatria: perspectiva dos enfermeiros. Dissertação (Mestrado em Enfermagem de Saúde Infantil e Pediatria) - Escola Superior de Enfermagem do Porto, Portugal, 2012.

MARQUES, C. D. C. et al. O cuidador familiar da criança hospitalizada na visão da equipe de enfermagem. Cienc Cuid Saude. V.13, n.3, p. 541-548, 2014.

MELO, E. M. O. P. et al. Envolvimento dos pais nos cuidados de saúde de crianças hospitalizadas. Rev. Latino-Am. Enfermagem., v.22, n. 3. p. 432-9, 2014.

PONTES, E. P. et al. Comunicação não verbal na unidade de terapia intensiva pediátrica: percepção da equipe multidisciplinar. REME, v. 18, n. 1, p. 158-163, 2014.

REIS, A. G. A presença da família durante procedimentos invasivos e de ressuscitação em pediatria. Rev Paul Pediatr., v. 33, p. 377-378, 2015.

ROSSI, C. S.; RODRIGUES, B. M. R. D. Típico da ação do profissional de enfermagem quanto ao cuidado familial da criança hospitalizada. Acta Paul Enferm., v.23, n.5, p. 640-5, 2010.

SCHNEIDER, C. M.; MEDEIROS, L. G. Criança hospitalizada e o impacto emocional gerado nos pais. Unoesc \& Ciência - ACHS, v. 2, n. 2, p. 140-154, 2011

SOUSA, L. D.; GOMES, G. C.; SANTOS, C. P. Percepções da Equipe de Enfermagem Acerca da Importância da Presença do Familiar/Acompanhante no Hospital. Rev. enferm. UERJ, v.17, n.3, p. 394-9, 2009.

XAVIER, D. M. et al. A família revelando-se como um ser de direitos durante a internação hospitalar da criança. Rev. Bras. Enferm., Brasília , v. 66, n. 6, p. 866-872, 2013.

XAVIER, D. M. et al. A família na Unidade de Pediatria: convivendo com normas e rotinas hospitalares. Rev Bras Enferm., v.67, n.2, p. 181-6, 2014.

Recebido em: 10 de outubro de 2016 Aceito em: 10 de abril de 2017 